\title{
Plant invasion modifies isohydricity in Mediterranean tree species
}

\author{
Simon Haberstroh ${ }^{1}$, Raquel Lobo-do-Vale ${ }^{2}$, Maria Caldeira ${ }^{2}$, Maren Dubbert ${ }^{3}$, Matthias \\ Cuntz $^{4}$, and Christiane Werner ${ }^{1}$ \\ ${ }^{1}$ University of Freiburg \\ ${ }^{2}$ University of Lisbon Forest Research Centre \\ ${ }^{3}$ Albert-Ludwigs-Universitat Freiburg \\ ${ }^{4}$ Université de Lorraine
}

May 2, 2021

\begin{abstract}
Knowledge of plant hydraulic strategies (isohydric vs anisohydric) is crucial to predict the response of plants to changing environmental conditions, such as climate-change induced extreme drought. Several abiotic factors, such as evaporative demand, have been shown to seasonally modify the isohydricity of plants, however, the impact of biotic factors, such as plant-plant interactions on hydraulic strategies has seldom been explored. Here, we investigated adaptations in hydraulic strategies for two woody species in response to seasonal abiotic conditions, experimental drought and plant invasion in a Mediterranean cork oak (Quercus suber) ecosystem with a combined shrub invasion (Cistus ladanifer) and rain exclusion experiment. From summer to winter, the degree of isohydricity shifted from partial isohydric to anisohydric in $Q$. suber and inversely from strict anisohydric to partial isohydric for C. ladanifer. During drought, plant invasion significantly modified the hydraulic strategy of invaded $Q$. suber to a higher degree of anisohydricity with severe negative consequences for tree functioning, implying progressive leaf and xylem damage. The rain exclusion alone led to a non-significant increase in anisohydricity for both species. We demonstrate that the degree of isohydricity of plants is dynamically determined by the interplay of species-specific hydraulic traits and their abiotic and biotic environment.
\end{abstract}

\section{Hosted file}

Haberstroh et al. 2021 Main document.pdf available at https://authorea.com/users/411451/ articles/520479-plant-invasion-modifies-isohydricity-in-mediterranean-tree-species 

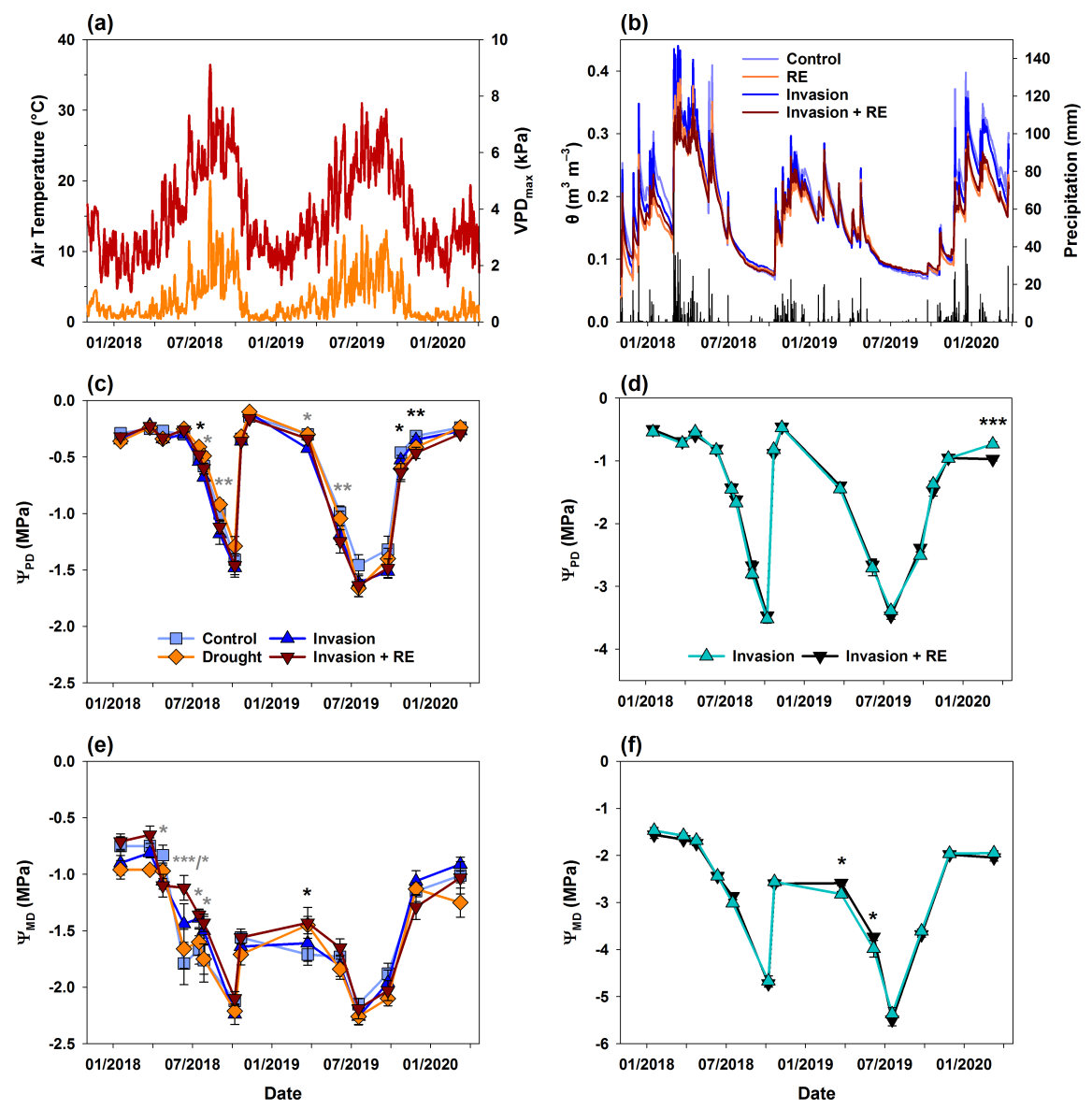

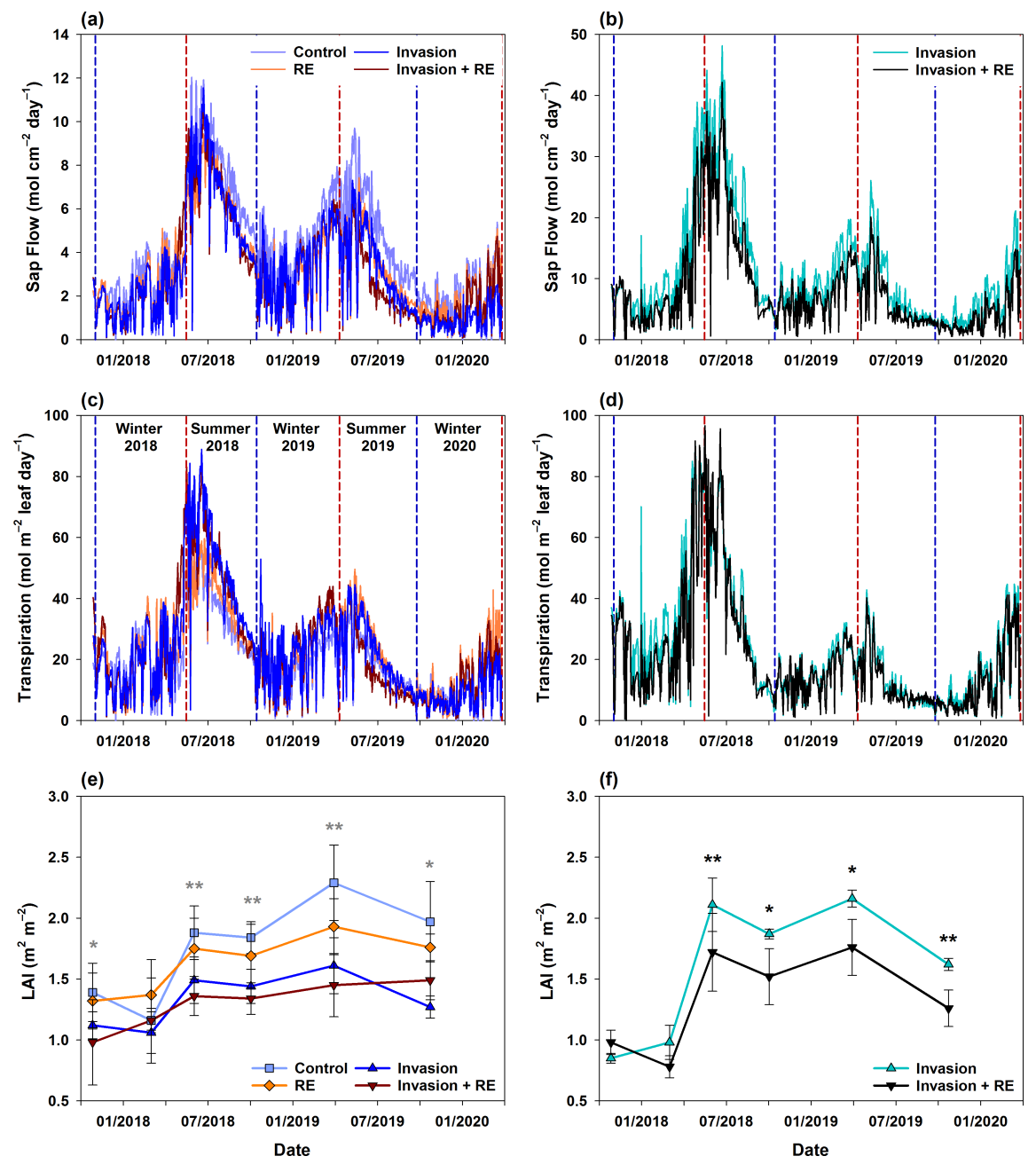

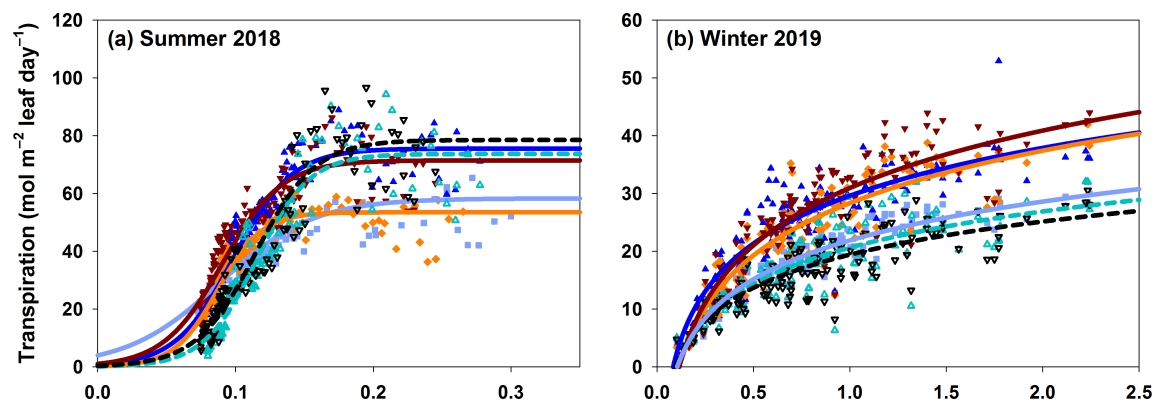

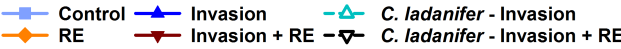
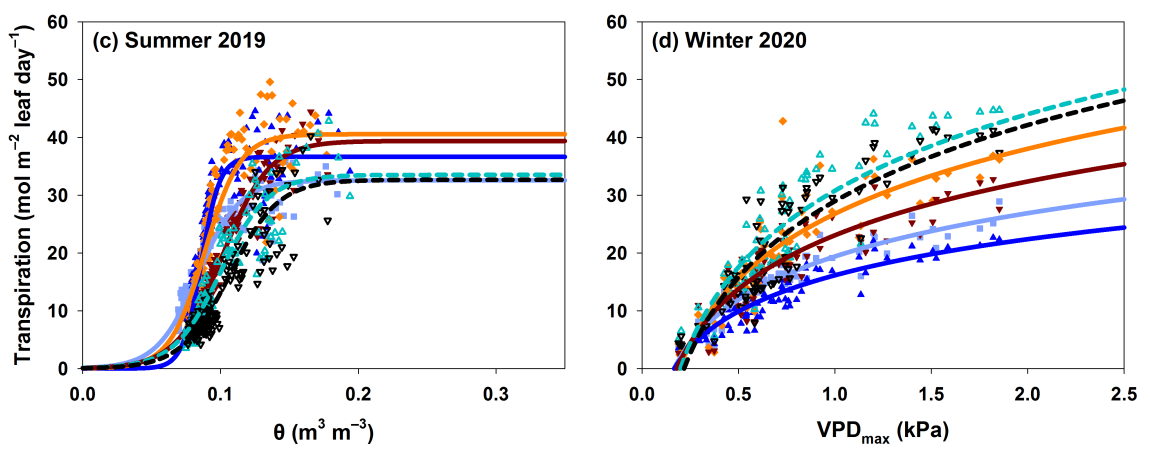

(a) Q. suber

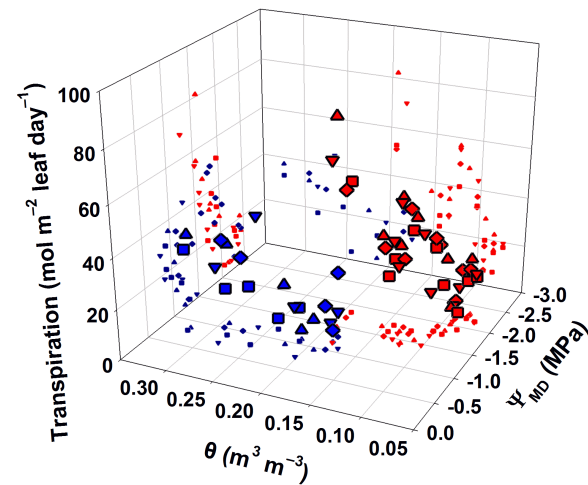

(b) C. Iadanifer

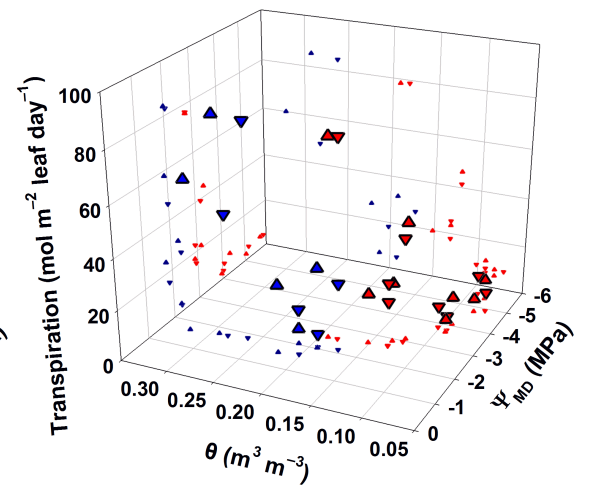

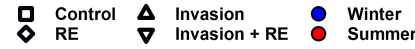

$\begin{array}{llll}\Delta & \text { Invasion } & \bullet & \text { Winter } \\ \boldsymbol{\nabla} & \text { Invasion + RE } & \text { ○ } & \text { Summer }\end{array}$ 

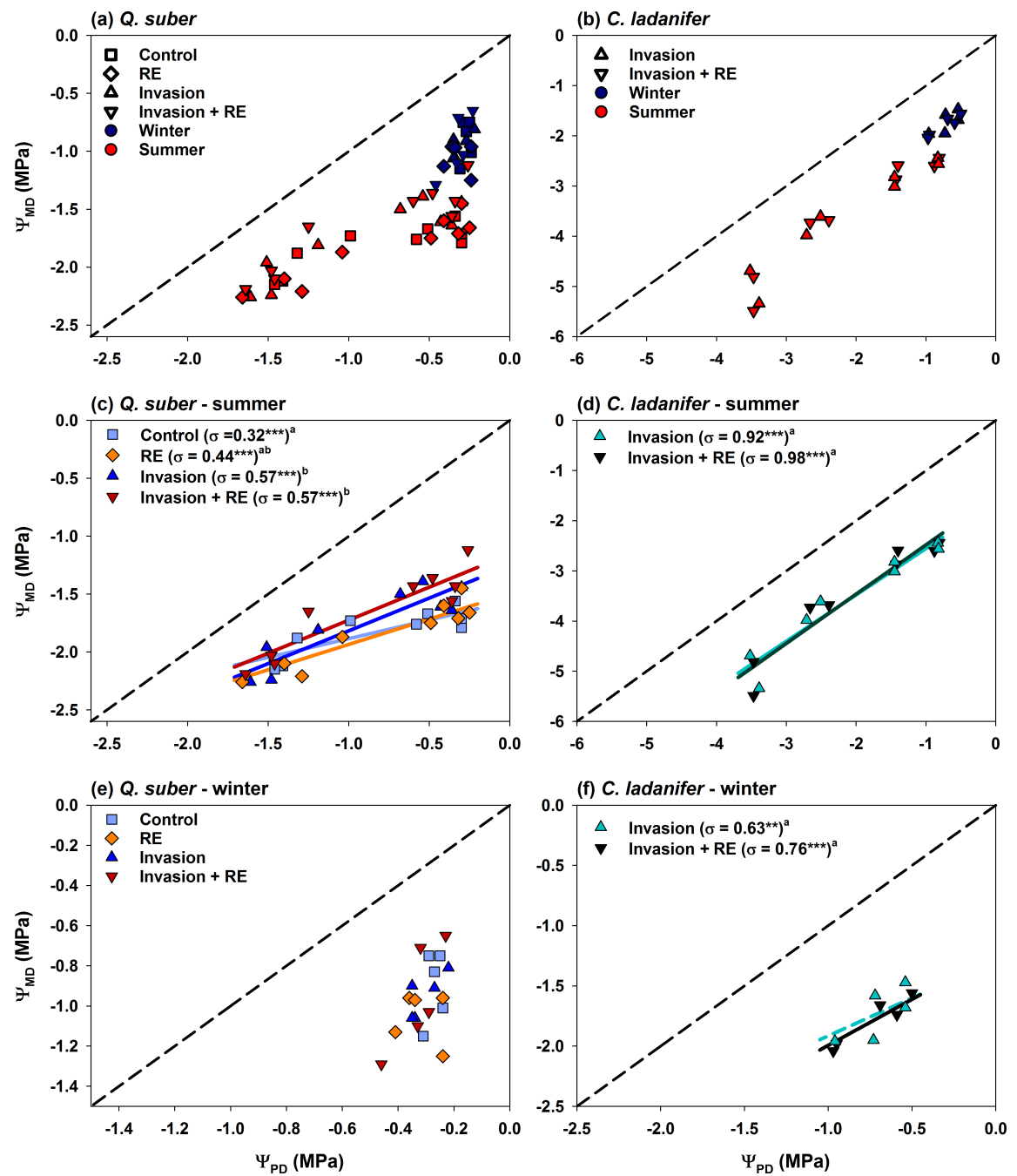
(a) seasonal effects

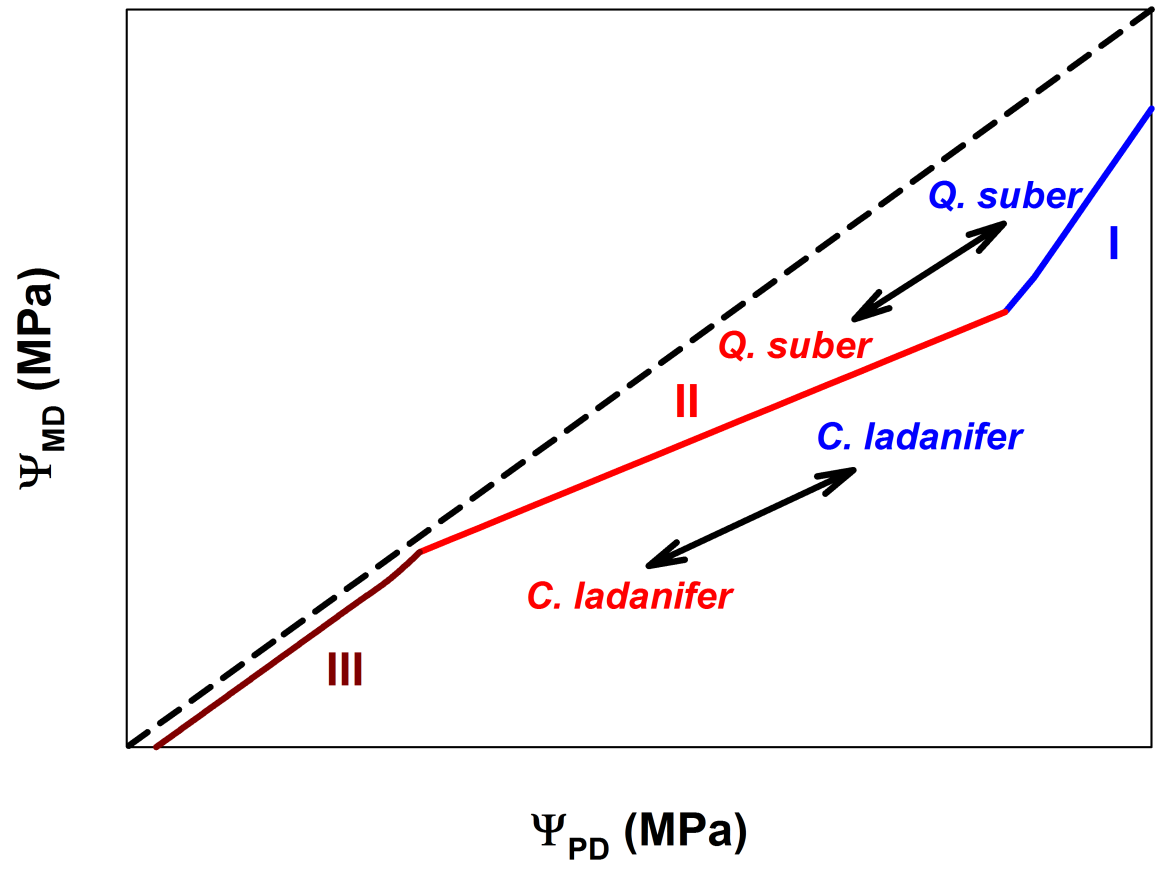

(b) plant invasion effects

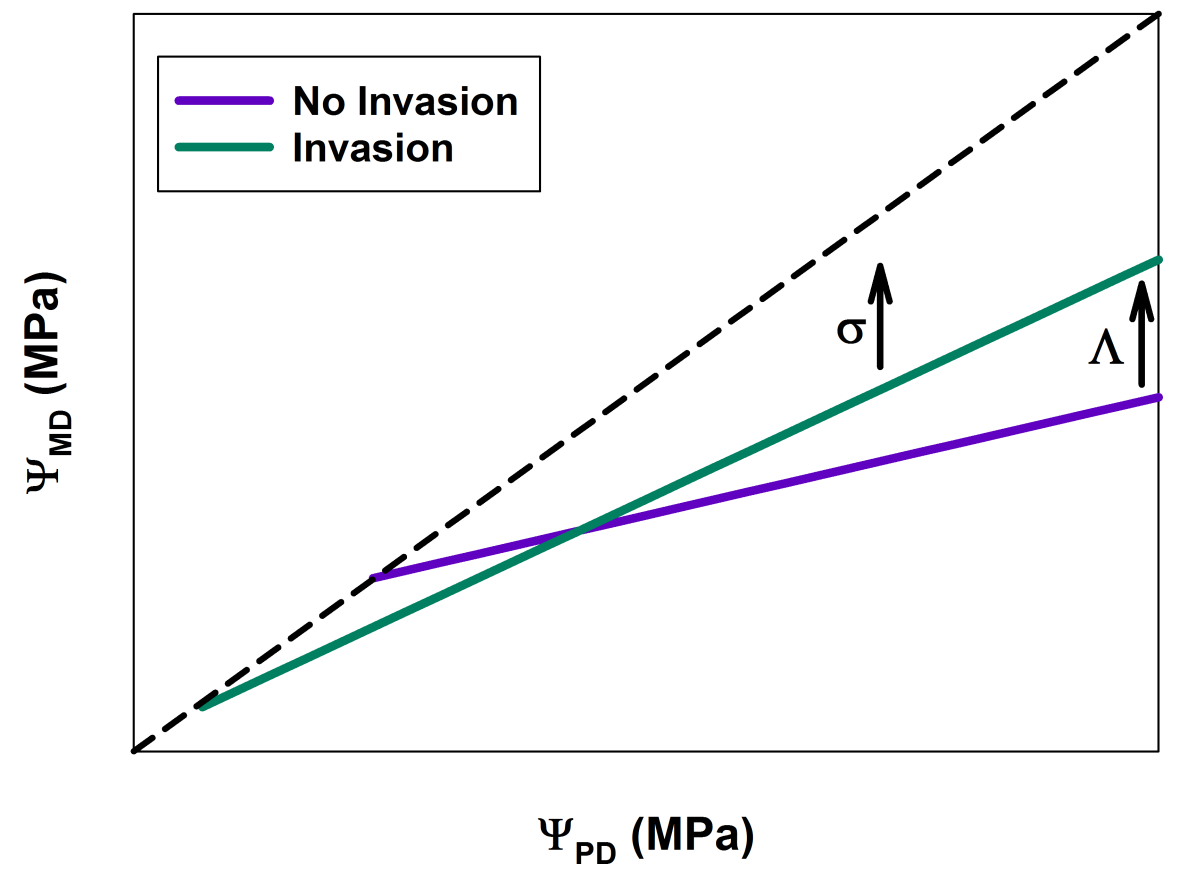

